\title{
Lymph node ratio as a prognostic factor in elderly patients with pathological N1 non-small cell lung cancer
}

\author{
Juan P Wisnivesky, ${ }^{1,2}$ Jacqueline Arciniega, ${ }^{1}$ Grace Mhango, ${ }^{1}$ John Mandeli, ${ }^{3}$ \\ Ethan A Halm ${ }^{4}$
}

\section{See Editorial, p 271}

1 Divisions of General Internal Medicine, Mount Sinai School of Medicine, New York, New York, USA

${ }^{2}$ Division of Pulmonary, Critical Care, and Sleep Medicine, Mount Sinai School of Medicine, New York, New York, USA

${ }^{3}$ Department of Preventive Medicine, Mount Sinai School of Medicine, New York, New York, USA

${ }^{4}$ Departments of Internal Medicine and Clinical Sciences, University of Texas

Southwestern Medical Center, Dallas, Texas, USA

\section{Correspondence to}

Juan P Wisnivesky, Department of Medicine, Mount Sinai School of Medicine, One Gustave L Levy Place, Box 1087, New York, NY 10029, USA: juan.wisnivesky@mssm.edu

Received 6 August 2010 Accepted 4 November 2010 Published Online First 2 December 2010

\begin{abstract}
Background Lymph node (LN) metastasis is an important predictor of survival for patients with non-small cell lung cancer (NSCLC). However, the prognostic significance of the extent of $L N$ involvement among patients with $\mathrm{N} 1$ disease remains unknown. A study was undertaken to evaluate whether involvement of a higher number of $\mathrm{N} 1 \mathrm{LNs}$ is associated with worse survival independent of known prognostic factors.

Methods Using the Surveillance, Epidemiology and End Results-Medicare database, 1682 resected patients with N1 NSCLC diagnosed between 1992 and 2005 were identified. As the number of positive LNs is confounded by the total number of LNs sampled, the cases were classified into three groups according to the ratio of positive to total number of $\mathrm{LNs}$ removed (LN ratio (LNR)): $\leq 0.15,0.16-0.5$ and $>0.5$. Lung cancerspecific and overall survival was compared between these groups using Kaplan-Meier curves. Stratified and Cox regression analyses were used to evaluate the relationship between the LNR and survival after adjusting for potential confounders.
\end{abstract}

Results Lung cancer-specific and overall survival was lower among patients with a high LNR $(p<0.0001$ for both comparisons). Median lung cancer-specific survival was 47 months, 37 months and 21 months for patients in the $\leq 0.15,0.16-0.5$ and $>0.5$ LNR groups, respectively. In stratified and adjusted analyses, a higher LNR was also associated with worse lung cancerspecific and overall survival.

Conclusions The extent of LN involvement provides independent prognostic information in patients with N1 NSCLC. This information may be used to identify patients at high risk of recurrence who may benefit from aggressive postoperative therapy.

\section{INTRODUCTION}

The status of regional lymph node (LN) is a strong prognostic indicator and has a major impact on treatment decisions for patients with non-small cell lung cancer (NSCLC). Involvement of peribronchial, hiliar or intrapulmonary LNs is one of the stronger predictors of lung cancer survival; 5-year survival rates are approximately $70 \%$ in patients with N0 disease compared with only $40 \%$ for patients with involvement of N1 nodes. ${ }^{1}$ Despite the strong correlation with survival, there is considerable variability in the outcomes of patients with N1 disease, even after controlling for T status. These findings have generated considerable interest in identifying patterns of LN involvement that more accurately predict survival, particularly of patients with $\mathrm{N} 1$ disease. ${ }^{2-6} \mathrm{~N} 1$-positive patients have a considerable risk of recurrence; thus, these data could provide useful prognostic information to physicians and patients, would allow the selection of patients for more aggressive postoperative therapy, and may help identify tumours with more aggressive behaviour.

The number of positive LNs may influence survival of patients with N1 NSCLC. Several single institutional studies have shown worse outcomes among patients with involvement of multiple N1 LNs. ${ }^{7-11}$ Based on these results, some authors have proposed a revised classification system dividing N1 disease into subcategories according to the number of positive LNs. A limitation in evaluating the association between survival and the number of positive LNs is that this factor is inherently confounded by the number of removed LNs. To address the potential limitation, the LN ratio (LNR) has been used to assess the prognosis of the extent of LN involvement in several other diseases such as colon, bladder, gastric and pancreatic cancer. ${ }^{12-16}$ The LNR has also been evaluated in a lung cancer study. ${ }^{9}$

Using national data from the Surveillance Epidemiology and End Results (SEER) registry linked to Medicare records, we evaluated the relationship between the LNR and survival of patients with resected NSCLC with N1 involvement. Our hypothesis was that a higher LNR is an independent predictor of worse prognosis.

\section{METHODS}

Patients with NSCLC were identified from the Surveillance, Epidemiology and End Results (SEER)-Medicare registry. The SEER program collects data on all new cases of cancer from several population-based registries covering approximately $26 \%$ of the US population. The study cohort consisted of 1682 patients >65 years of age with pathologically N1 NSCLC diagnosed between 1992 and 2005. Patients who were diagnosed at autopsy or from death certificate data were excluded, as well as those who received neoadjuvant chemotherapy (that may lead to downstaging), underwent limited resection (segmentectomy or wedge resection) or had incomplete data on the number of LNs involved or sampled during surgery. Preoperative comorbidities and use of neoadjuvant chemotherapy can only be assessed using Medicare claims before surgery. We therefore also excluded patients who were enrolled in a health maintenance 
organisation, who were not covered by Medicare parts $\mathrm{A}$ and $\mathrm{B}$ or who were 65 years of age at the time of surgery.

Sociodemographic characteristics were obtained from SEER and the Medicare database. Socioeconomic status was estimated based on the median income for the ZIP code of the patient's residence available in the Medicare file. Comorbidities were ascertained using the Deyo adaptation of the Charlson comorbidity index, applying lung cancer-specific weights. ${ }^{17}$

Stage was classified according to the latest revision of the 7 th edition of the TNM classification for lung cancer. ${ }^{18}$ Data regarding tumour location, size, extension and histology was obtained from SEER. SEER collects detailed data regarding the status of $\mathrm{LN}$ involvement including the total number of regional LNs that were sampled as well as the number of positive LNs. Using this information, we calculated the LNR as the ratio between the number of positive $\mathrm{N} 1$ nodes and the number of LNs removed from all nodal stations during surgery. Based on prior studies and on the distribution of the LNR in SEER, patients were classified into three LNR groups: $\leq 0.15,0.16-0.5$ and $>0.5 .^{9} 19$

The type of surgery (lobectomy vs pneumonectomy) was categorised using SEER codes and the date of surgery was obtained from Medicare files. Radiation therapy use was ascertained from SEER and Medicare claims. ${ }^{20} 21$ Patients were considered as treated with adjuvant chemotherapy if data from Medicare claims indicated that the individual received chemotherapy within 3 months of surgery. ${ }^{22}$

\section{Statistical analysis}

Differences in distribution of baseline characteristics between patients in the three LNR groups were evaluated using the $\chi^{2}$ test. The Kaplan-Meier method was used to estimate survival among the patients in the three LNR categories. As the objective of the study was to evaluate the prognostic significance of the LNR, we used lung cancer-specific mortality as the primary study outcome as it allows for controlling for unrelated deaths. To calculate disease-specific survival, deaths attributed to causes other than lung cancer were censored at the date of death. Cause of death information in SEER is provided by the National Center for Health Statistics and obtained from state death certificates. Secondary analyses used overall survival data. Survival was determined as the interval from the date of surgery to the date of death. Those surviving past 31 December 2007 were classified as censored.

The survival of patients within the three LNR groups was compared after stratifying the sample tumour status, an established prognostic factor, as well as other key covariates. We conducted secondary analyses evaluating whether the total number of positive LNs $(\leq 2,3$ and $\geq 4)$ was associated with survival among patients with $>10 \mathrm{LNs}$ sampled (the extent of LN sampling recommended in the literature). ${ }^{23}$ Cox regression models were used to evaluate the association between the LNR and survival after adjusting for age, sex, race/ethnicity, marital status, estimated income, comorbidities, histology, tumour status and location, type of surgery and use of chemotherapy or radiation therapy. We tested the assumption of proportionality of hazards using a log-log survival plot. All analyses were performed with SAS statistical package version 9.2 using two-sided $p$ values.

\section{RESULTS}

We identified 1682 patients with NSCLC aged $>65$ years with N1 disease from SEER-Medicare. Overall, $31 \%, 50 \%$ and $19 \%$ we classified into the $\leq 0.15,0.16-0.5$ and $>0.5$ LNR categories, respectively. The median number of LNs resected was 8 (IOR 8).
The distribution of age, race/ethnicity, marital status, comorbidities, tumour status and location were similar across the groups ( $p>0.05$ for all comparisons, table 1$)$. Patients with the highest LNR group were more likely to be female $(p<0.0001)$, to have adenocarcinomas $(p=0.001)$ or to have undergone lobectomy $(p<0.0001)$. Postoperative radiotherapy was more frequently used in patients with the highest LNR group $(p<0.0001)$; however, there were no significant differences in the use of adjuvant chemotherapy $(\mathrm{p}=0.09)$.

Unadjusted survival analyses showed that a higher LNR was associated with worse lung cancer-specific $(p<0.0001)$ and overall $(p<0.0001)$ survival (figure 1$)$. Median lung cancerspecific survival was 47 months, 37 months and 21 months for patients in the $\leq 0.15,0.16-0.5$ and $>0.5$ LRN groups, respectively. Analyses stratified by tumour status also showed a significant association between a higher LNR and worse lung cancer-specific survival in patients with T1, T2 or T3 disease (figure 2). Similarly, stratified analyses by age, sex, race/ ethnicity, marital status, income, histology, tumour location, type of surgery, number of LNs sampled and postoperative use of radiotherapy or chemotherapy showed worse lung cancerspecific and overall mortality in patients with a higher LNR ( $p<0.05$ for all comparisons). Secondary analyses restricted to patients with $>10$ LNs sampled showed that a higher number of positive LNs was similarly associated with worse lung cancerspecific $(p<0.0001)$ and overall $(p<0.0001)$ survival.

Cox regression analysis was performed to evaluate the prognostic significance of the LNR after adjusting for potential confounders. As shown in table 2, the LNR was an independent predictor of survival with higher values associated with an increased risk of lung cancer-specific and overall mortality. Compared with patients in the lowest LNR group $(\leq 0.15)$, the hazard of lung cancer-related death was 1.26 (95\% CI 1.07 to 1.48 ) and 1.92 (95\% CI 1.57 to 2.34) times greater for patients in the $0.16-0.5$ and $>0.5$ LNR categories, respectively. Similarly, overall survival decreased with higher LNR (HR 1.31, 95\% CI 1.14 to 1.50 and HR $1.88,95 \%$ CI 1.58 to 2.34 for patients in the $0.16-0.5$ and $>0.5$ LNR categories, respectively).

\section{DISCUSSION}

Accurate staging is critical for providing prognostic information to patients with lung cancer and for selecting the most appropriate therapeutic interventions. The status of LNs is one of the main determinants of survival in NSCLC and an essential component of the revised 7 th edition of the TNM classification for lung cancer. ${ }^{18}$ Using nationally representative data from over 1600 resected patients $>65$ years of age with pathologically N1 disease, we found that involvement of a higher number of LNs (expressed as the LNR) is a marker of worse survival independent of tumour status, tumour size and other known prognostic factors. These results suggest that the LNR is an independent prognostic factor for patients with N1 NSCLC.

The 7th edition of the TNM classification for lung cancer is universally accepted as the most useful staging system for NSCLC. ${ }^{18}$ According to these criteria, LN involvement is classified into four groups: N0 (no regional LN metastasis), N1 (metastasis to ipsilateral peribronchial or hilar LNs), N2 (metastasis to ipsilateral mediastinal or subcarinal $\mathrm{LNs}$ ) and $\mathrm{N} 3$ (metastasis to contralateral and supraclavicular LNs). It is established that longterm survival rapidly decreases with more extensive LN metastasis. ${ }^{1}$ A few studies have suggested that, among patients with N1 disease, the number of involved LNs may provide additional prognostic information. ${ }^{7-11}$ In a study of 1081 patients with stage I-IIIA NSCLC (N0-N2 disease), Lee et al showed 
Table 1 Baseline characteristics of patients with N1 lymph node involvement in SEER-Medicare

\begin{tabular}{|c|c|c|c|c|}
\hline \multirow[b]{2}{*}{ Characteristic } & \multicolumn{3}{|l|}{ Lymph node ratio } & \multirow[b]{2}{*}{ p Value } \\
\hline & $\leq 0.15(N=524)$ & $0.16-0.50(\mathrm{~N}=849)$ & $\geq 0.5(\mathrm{~N}=309)$ & \\
\hline \multicolumn{5}{|l|}{ Age (years), N (\%) } \\
\hline$\leq 70$ & $191(36)$ & $303(36)$ & $108(35)$ & \multirow[t]{3}{*}{0.980} \\
\hline $71-75$ & $165(31)$ & $279(32)$ & $103(33)$ & \\
\hline$>75$ & $168(32)$ & $267(31)$ & $98(32)$ & \\
\hline Female, N (\%) & $200(38)$ & $379(45)$ & $171(55)$ & $<0.0001$ \\
\hline \multicolumn{5}{|l|}{ Race/ethnicity, N (\%) } \\
\hline White & $483(92)$ & $744(88)$ & $270(87)$ & \multirow[t]{3}{*}{0.061} \\
\hline African American & $18(3)$ & $35(4)$ & $18(6)$ & \\
\hline Hispanic/other* & $23(4)$ & $70(8)$ & $21(7)$ & \\
\hline Married, N (\%) & $326(62)$ & $531(63)$ & $179(58)$ & 0.338 \\
\hline \multicolumn{5}{|c|}{ Median income in ZIP code of residence, $\mathrm{N}(\%) \dagger$} \\
\hline Lowest quartile & $127(24)$ & $186(22)$ & $73(23)$ & \multirow[t]{4}{*}{0.682} \\
\hline Second quartile & $128(24)$ & $221(26)$ & $69(22)$ & \\
\hline Third quartile & $126(24)$ & $223(26)$ & $87(28)$ & \\
\hline Highest quartile & $143(27)$ & $215(25)$ & $80(26)$ & \\
\hline \multicolumn{5}{|l|}{ Comorbidity score, N (\%) } \\
\hline$\leq 1$ & $190(36)$ & $339(40)$ & $117(38)$ & \multirow[t]{3}{*}{0.445} \\
\hline $1-2$ & $195(37)$ & $290(34)$ & $120(39)$ & \\
\hline$>2$ & $139(27)$ & $220(26)$ & $72(23)$ & \\
\hline \multicolumn{5}{|l|}{ Tumour status, N (\%) } \\
\hline $\mathrm{T} 1 \mathrm{~A}$ & $61(12)$ & $95(11)$ & $28(9)$ & \multirow[t]{5}{*}{0.364} \\
\hline $\mathrm{T} 1 \mathrm{~B}$ & $82(16)$ & $148(17)$ & $59(19)$ & \\
\hline $\mathrm{T} 2 \mathrm{~A}$ & $234(45)$ & $388(46)$ & $152(49)$ & \\
\hline $\mathrm{T} 2 \mathrm{~B}$ & $54(10)$ & $98(12)$ & $32(10)$ & \\
\hline $\mathrm{T} 3$ & $93(18)$ & $120(14)$ & $38(12)$ & \\
\hline \multicolumn{5}{|l|}{ Histology, N (\%) } \\
\hline Adenocarcinoma & $222(42)$ & $408(48)$ & $175(57)$ & \multirow[t]{5}{*}{0.001} \\
\hline Squamous cell carcinoma & $219(42)$ & $293(35)$ & $81(26)$ & \\
\hline Large cell carcinoma & $32(6)$ & $62(7)$ & $17(6)$ & \\
\hline Bronchioloalveolar cell carcinoma & $29(6)$ & $49(6)$ & $25(8)$ & \\
\hline Other & $22(4)$ & 37 (4) & $11(4)$ & \\
\hline \multicolumn{5}{|l|}{ Tumour location, N (\%) } \\
\hline Upper lobe & $287(55)$ & $450(53)$ & $149(48)$ & \multirow[t]{3}{*}{0.118} \\
\hline Lower lobe & $186(36)$ & $337(40)$ & $128(41)$ & \\
\hline Other location & $51(10)$ & $62(7)$ & $32(10)$ & \\
\hline \multicolumn{5}{|l|}{ Type of surgery, N (\%) } \\
\hline Lobectomy & $410(78)$ & $722(85)$ & $281(91)$ & \multirow[t]{2}{*}{$<0.0001$} \\
\hline Pneumonectomy & $114(22)$ & $127(15)$ & 28 (9) & \\
\hline \multicolumn{5}{|l|}{ Postoperative radiation therapy, $\mathrm{N}(\%)$} \\
\hline Yes & $135(26)$ & $362(43)$ & $158(51)$ & \multirow[t]{2}{*}{$<0.0001$} \\
\hline No & $389(74)$ & $487(57)$ & $151(49)$ & \\
\hline \multicolumn{5}{|l|}{ Adjuvant chemotherapy, N (\%) } \\
\hline Yes & $88(17)$ & $177(21)$ & $69(22)$ & \multirow[t]{2}{*}{0.091} \\
\hline No & $436(83)$ & $672(79)$ & $240(78)$ & \\
\hline
\end{tabular}

${ }^{*}$ Categories were combined to avoid reporting cells with small numbers of patients.

†Income data missing for four study subjects.

that a higher number of N1 LN metastases was associated with worse prognosis. ${ }^{10}$ More recently, a study of 415 resected patients with NSCLC with N1 or N2 LN metastasis reported that an elevated LNR was a risk factor for a poor prognosis. ${ }^{9}$ Conversely, other studies showed no association between the number of N1 nodes and survival. ${ }^{2} 2425$ Previous studies were conducted using case series from single referral centres, many had a limited number of cases of lung cancer, included patients with N2 or N3 disease and used different definitions to categorise the number of LNs involved with cancer. These factors may explain the discrepancy in findings across studies.

Our study found a strong association between the LNR and lung cancer survival in a large nationally representative and relatively homogenous cohort of unselected patients with resected N1 NSCLC. Adjusted analyses showed that the increased hazard of death conferred by an elevated LNR $(>0.5)$ is comparable to finding T3 disease and is independent of other prognostic factors. Our results are also consistent with the findings of several recent studies evaluating the relationship between the LNR and survival for other cancer types such as colon cancer, breast, gastric and bladder cancer, further supporting the validity of our findings.

The independent information provided by the LNR could be used to identify patients at high risk of recurrence who should undergo more aggressive postoperative therapies. Based on the results of several randomised controlled trials, current NSCLC treatment guidelines strongly endorse the use of adjuvant platinum-based chemotherapy for patients with stage II and IIIA NSCLC. ${ }^{26}$ However, adjuvant chemotherapy may provide little benefit to patients at low risk of recurrence while exposing them 

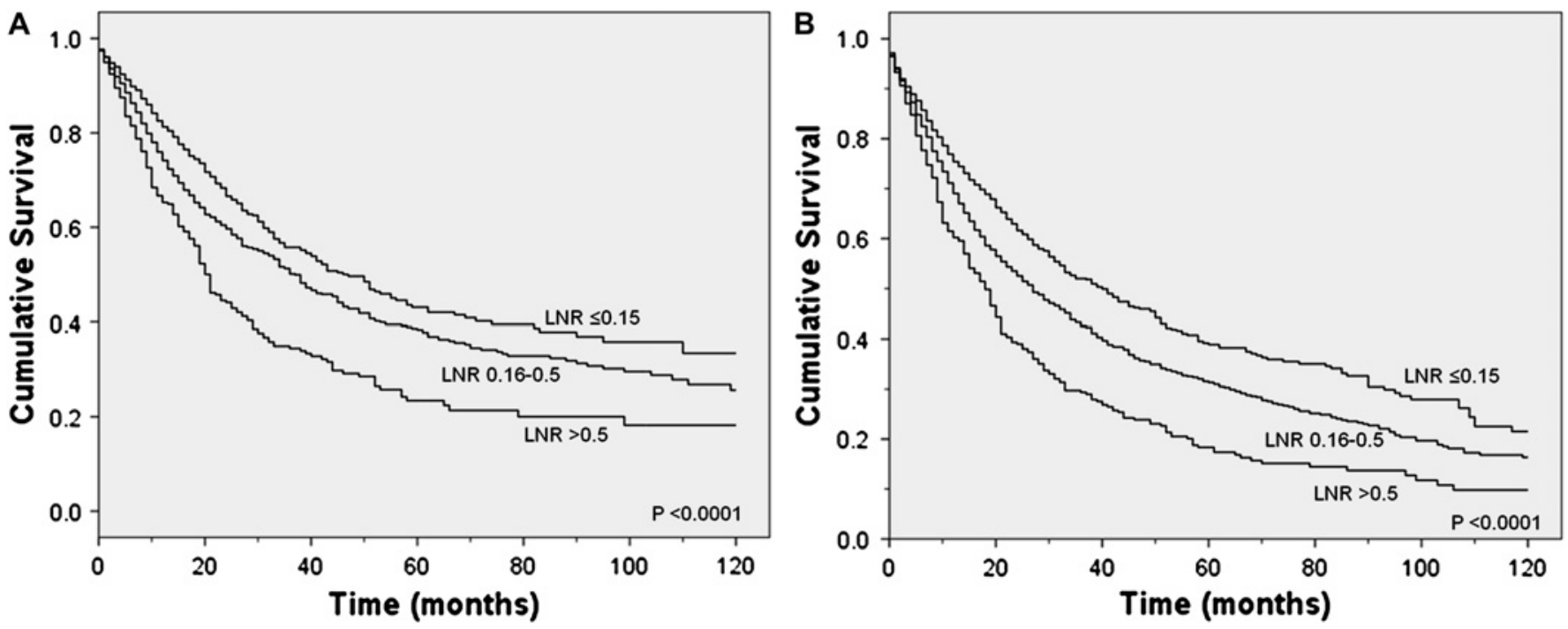

Figure 1 (A) Lung cancer-specific and (B) overall survival according to the ratio of positive to total N1 lymph nodes examined. LNR, lymph node ratio.

to potential toxicities or an increase risk of late mortality. ${ }^{27}$ Thus, more precise risk stratification may help avoid unnecessary toxicity among patients expected to be at low risk for recurrence after surgery. Additionally, the LNR could be used to provide more accurate prognostic information to patients with lung cancer and their families. These data should be useful in making informed decisions about therapeutic options and advanced directives, among other issues. Finally, the LNR may contribute towards better understanding of the underlying tumour biology as an increased number of positive LNs or a high LNR appears to be a phenotypic marker of a more aggressive disease. Improving staging and outcome prediction using biomarkers or gene expression profile is an active area of lung cancer research. ${ }^{28-30}$ The current strategy to identify new prognostic markers for lung cancer usually involves assessing the association of specific biomarkers or gene expression profiles with survival or cancer recurrence, thus requiring long-term follow-up data. If the validity of the LNR or the number of positive nodes and/or as a marker of aggressive tumour behaviour is validated in further studies, the LNR (which is readily available following surgery) could be used as an alternative or complementary phenotypic factor to rapidly screen for putative cancer biomarkers.

Current guidelines on lung cancer surgery do not specify the number of LNs that should be sampled for adequate staging. This lack of consensus generates wide practice variability among thoracic surgeons as shown in previous SEER studies. ${ }^{23}{ }^{31}$ As the total number of $\mathrm{N} 1$ nodes is limited by the total number of LNs sampled, we used the LNR, an index that allows evaluation of the extent of LN involvement while controlling for the number of LNs evaluated. However, secondary analyses limited to patients with $>10$ LNs sampled also found that a higher number of positive LNs was associated with worse survival. Large studies have suggested that at least $11 \mathrm{LNs}$ should be removed during surgery for optimal staging of lung cancer. ${ }^{23}$ If these recommendations are consistently adopted by thoracic surgeons, the absolute number of LNs may be used in the future as an alternative prognostic marker.

Several strengths and limitations of the study should be noted. The SEER-Medicare database is a population-based sample of cancer cases and is less affected by selection bias and unique practice patterns that are common in case series from single referral centres. The rigorous procedures followed by SEER registries allow for levels of ascertainment in participating areas as high as $98 \%$, showing that most eligible cases are captured in the registry. Thus, the generalisability of our findings should be excellent. Additionally, the large number of patients in the registry allowed us to assess the importance of the LNR among a homogenous cohort of patients with N1 disease and perform stratified analyses within key subgroups (tumour status, radiation therapy use, etc). However, as the study cohort included patients treated by different providers at multiple institutions, there was no uniform process for $\mathrm{LN}$ sampling or to establish the absence of N2 disease. We therefore cannot exclude the possibility that some patients with N2 LN involvement were included in the study.

In order to better examine the relationship between the LNR and disease progression, we used lung cancer-specific survival as the primary study outcome. The cause of death in the SEER registry is abstracted from death certificates and thus may not be accurate in some cases. However, for lung cancer the underlying cause of death was found to be $>90 \%$ accurate in a large registry. ${ }^{32}$ Additionally, we confirmed our results in secondary analyses using all-cause mortality. Our study was limited to Medicare beneficiaries who were $>65$ years of age; these results should therefore be validated among younger patients with NSCLC in the future. Exclusion of patients in SEER who were diagnosed with lung cancer before 65 years of age, however, allowed us to exclude individuals who received neoadjuvant chemotherapy and to control for the use of postoperative chemotherapy and radiation.

There were some differences in the baseline characteristics of patients in the three LNR groups. A high LNR was more common among women, a factor associated with increased lung cancer survival. $^{33}$ Similarly, postoperative radiotherapy use was more common among patients with a higher LNR. Whether postoperative radiation is beneficial or potentially detrimental for patients with resected N1 disease remains unclear. ${ }^{34}$ However, the association between a higher LNR and worse prognosis was consistently present in stratified and multivariate analyses, suggesting that our findings were not explained by potential confounders such as tumour status, sex, histological type or use of adjuvant therapy.

Molecular profiling is expected to improve prognosis assessments in lung cancer and inform treatment decisions. Although several genetic profiles have been published in the literature, 

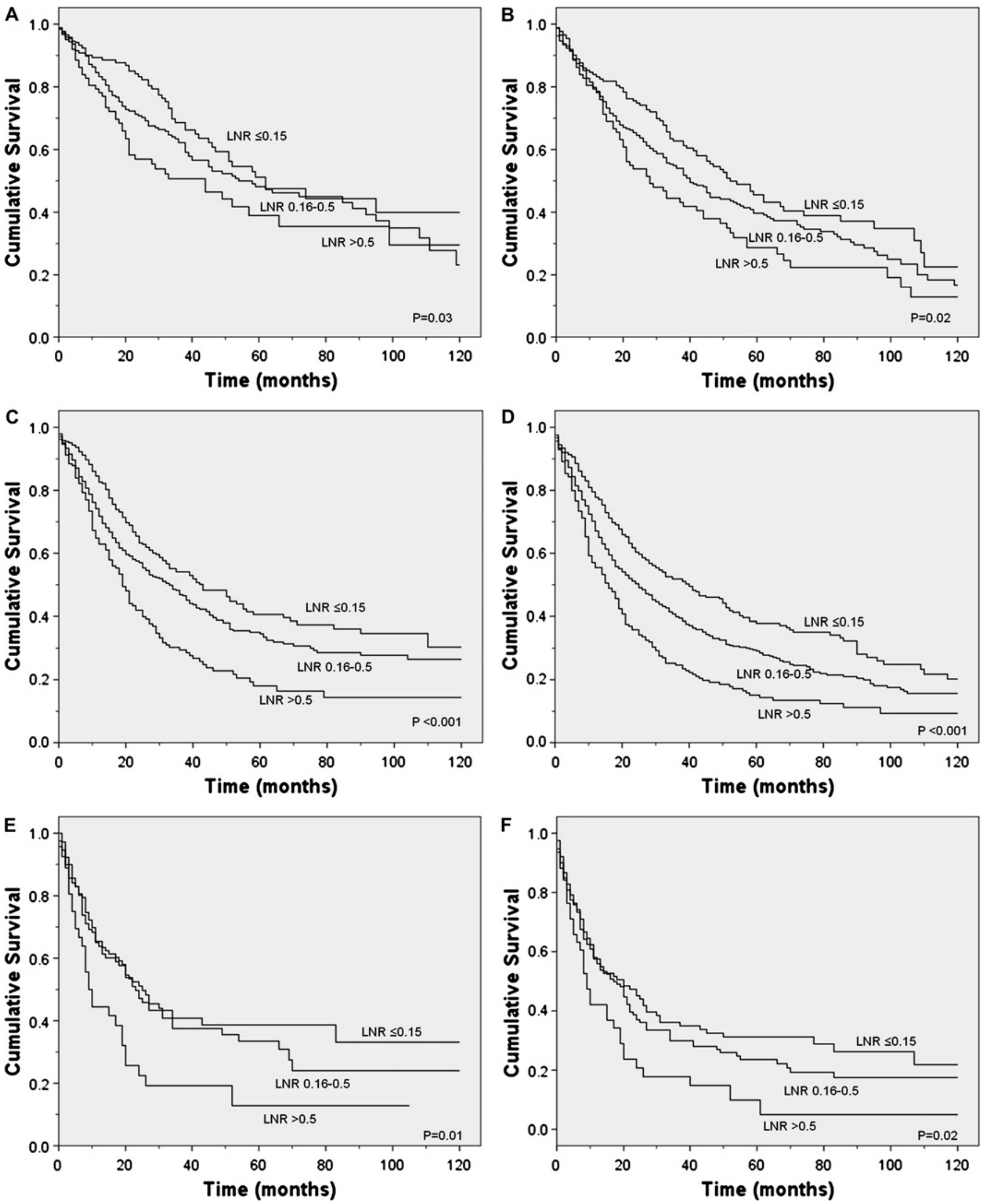

Figure 2 Lung cancer-specific and overall survival according to the ratio of positive to total N1 lymph nodes examined during surgery among patients with $(A, B) T 1 ;(C, D) T 2$; and $(E, F)$ T3 disease.

none has yet been validated or incorporated into routine clinical practice. ${ }^{35}$ Even if available in the future, it is expected that these approaches will be used in combination and not replace pathological staging. The LNR is readily available from the routine pathological report without additional costs so could be rapidly incorporated into clinical practice. Future studies should assess whether the LNR is also an independent prognostic factor among patients with $\mathrm{N} 2$ disease. 
Table 2 Adjusted association between the lymph node ratio and survival of patients with N1 lung cancer

\begin{tabular}{|c|c|c|}
\hline Variable & $\begin{array}{l}\text { Lung cancer-specific } \\
\text { survival HR }\left(95 \% \mathrm{Cl}^{*}\right)\end{array}$ & $\begin{array}{l}\text { Overall survival } \\
\text { HR }(95 \% \mathrm{CI})\end{array}$ \\
\hline \multicolumn{3}{|l|}{ Lymph node ratio } \\
\hline$\leq 0.15$ & Reference & Reference \\
\hline $0.16-0.5$ & $1.26(1.07$ to 1.48$)$ & $1.31(1.14$ to 1.50$)$ \\
\hline$>0.5$ & $1.92(1.57$ to 2.34$)$ & $1.88(1.58$ to 2.34$)$ \\
\hline Age, years & $1.02(1.01$ to 1.03$)$ & $1.02(1.01$ to 1.03$)$ \\
\hline Female & $0.82(0.71$ to 0.95$)$ & $0.80(0.70$ to 0.91$)$ \\
\hline \multicolumn{3}{|l|}{ Race/ethnicity } \\
\hline White & Reference & Reference \\
\hline Black & $0.69(0.48$ to 1.03$)$ & $0.79(0.58$ to 1.08$)$ \\
\hline Hispanic & $0.41(0.16$ to 0.96$)$ & $0.59(0.31$ to 1.10$)$ \\
\hline Other & $1.03(0.78$ to 1.37$)$ & $1.08(0.85$ to 1.37$)$ \\
\hline Married & $0.90(0.78$ to 1.05$)$ & $0.85(0.75$ to 0.97$)$ \\
\hline \multicolumn{3}{|c|}{ Median income in ZIP code of residence } \\
\hline Lowest quartile & Reference & Reference \\
\hline Second quartile & $0.97(0.80$ to 1.17$)$ & $1.02(0.87$ to 1.21$)$ \\
\hline Third quartile & $0.84(0.70$ to 1.03$)$ & $0.86(0.73$ to 1.02$)$ \\
\hline Highest quartile & $0.83(0.69$ to 1.02$)$ & $0.90(0.76$ to 1.06$)$ \\
\hline \multicolumn{3}{|l|}{ Comorbidity score, N (\%) } \\
\hline$\leq 1$ & Reference & Reference \\
\hline $1-2$ & $1.05(0.90$ to 1.25$)$ & $1.08(0.94$ to 1.23$)$ \\
\hline$>2$ & $1.32(1.11$ to 1.56$)$ & $1.42(1.23$ to 1.65$)$ \\
\hline \multicolumn{3}{|l|}{ Histology } \\
\hline Adenocarcinoma & Reference & Reference \\
\hline Bronchioloalveolar carcinoma & $0.97(0.74$ to 1.26$)$ & $0.91(0.71$ to 1.15$)$ \\
\hline Squamous cell carcinoma & $0.79(0.67$ to 0.93$)$ & $0.82(0.71$ to 0.94$)$ \\
\hline Large cell & $1.02(0.78$ to 1.34$)$ & $1.03(0.81$ to 1.30$)$ \\
\hline Other & $1.12(0.82$ to 1.56$)$ & $1.05(0.79$ to 1.40$)$ \\
\hline \multicolumn{3}{|l|}{ Tumour status } \\
\hline T1A & Reference & Reference \\
\hline $\mathrm{T} 1 \mathrm{~B}$ & $1.13(0.85$ to 1.50$)$ & $1.08(0.86$ to 1.37$)$ \\
\hline $\mathrm{T} 2 \mathrm{~A}$ & 1.55 (1.21 to 1.99$)$ & $1.36(1.10$ to 1.66$)$ \\
\hline $\mathrm{T} 2 \mathrm{~B}$ & $1.89(1.40$ to 2.55$)$ & $1.60(1.25$ to 2.06$)$ \\
\hline $\mathrm{T} 3$ & $2.05(1.54$ to 2.74$)$ & $1.77(1.40$ to 2.25$)$ \\
\hline \multicolumn{3}{|l|}{ Tumour location } \\
\hline Upper lobe & Reference & Reference \\
\hline Lower lobe & $1.16(1.01$ to 1.33$)$ & $1.08(0.97$ to 1.24$)$ \\
\hline Other location & $1.13(0.88$ to 1.46$)$ & $1.19(0.96$ to 1.47$)$ \\
\hline \multicolumn{3}{|l|}{ Type of surgery } \\
\hline Lobectomy & Reference & Reference \\
\hline Pneumonectomy & $1.26(1.04$ to 1.54$)$ & $1.23(1.03$ to 1.45$)$ \\
\hline Postoperative radiation therapy & $1.19(1.03$ to 1.37$)$ & $1.24(1.10$ to 1.40$)$ \\
\hline Adjuvant chemotherapy & $0.76(0.63$ to 0.91$)$ & $0.69(0.55$ to 0.75$)$ \\
\hline
\end{tabular}

${ }^{*}$ Adjusted HRs from model including all covariates listed in the table.

In summary, our study shows that the extent of LN involvement is an independent predictor of prognosis in patients with resected N1 NSCLC. Data regarding the LNR or the number of positive LNs could be used to provide patients with a more accurate assessment of prognosis. Additionally, these data suggest that patients with a high LNR are at risk of worse outcomes and should be considered for more aggressive postoperative treatments.

Acknowledgements The authors acknowledge the efforts of the Applied Research Branch, Division of Cancer Prevention and Population Science, National Cancer Institute; the Office of Information Services, and the Office of Strategic Planning, Center for Medicare and Medicaid Services; Information Management Services Inc; and the Surveillance, Epidemiology, and End Results Program tumour registries in the creation of the SEER-Medicare Database. The interpretation and reporting of these data are the sole responsibility of the authors.

Funding This study was supported by the National Cancer Institute (5R01CA131348-02).
Competing interests JPW is a member of the research board of EHE International and has received a grant from Glaxo Smith Kline for a COPD study and lecture fees from Novartis Pharmaceuticals.

Ethics approval The study was classified exempt by Mount Sinai's Institutional Review Board.

Provenance and peer review Not commissioned; externally peer reviewed.

\section{REFERENCES}

1. Mountain CF, Dresler CM. Regional lymph node classification for lung cancer staging. Chest 1997:111:1718-23.

2. Tanaka F, Yanagihara $\mathrm{K}$, Otake $\mathrm{Y}$, et al. Prognostic factors in patients with resected pathologic (p-) T1-2N1M0 non-small cell lung cancer (NSCLC). Eur J Cardiothorac Surg 2001;19:555-61.

3. van Rens MT, de la Riviere $A B$, Elbers $H R$, et al. Prognostic assessment of 2,361 patients who underwent pulmonary resection for non-small cell lung cancer, stage I II, and IIIA. Chest 2000:117:374-9.

4. van Velzen E, Snijder RJ, Brutel de la Riviere A, et al. Lymph node type as a prognostic factor for survival in T2 N1 M0 non-small cell lung carcinoma. Ann Thorac Surg 1997;63:1436-40.

5. Martini N, Flehinger BJ, Nagasaki F, et al. Prognostic significance of N1 disease in carcinoma of the lung. J Thorac Cardiovasc Surg 1983;86:646-53.

6. Marra A, Hillejan L, Zaboura G, et al. Pathologic N1 non-small cell lung cancer: correlation between pattern of lymphatic spread and prognosis. J Thorac Cardiovasc Surg 2003;125:543-53

7. Osaki T, Nagashima A, Yoshimatsu T, et al. Survival and characteristics of lymph node involvement in patients with $\mathrm{N} 1$ non-small cell lung cancer. Lung Cancer 2004:43:151-7.

8. Sayar A, Turna A, Kilicgun A, et al. Prognostic significance of surgical-pathologic multiple-station $\mathrm{N} 1$ disease in non-small cell carcinoma of the lung. Eur $J$ Cardiothorac Surg 2004;25:434-8.

9. Bria E, Milella M, Sperduti I, et al. A novel clinical prognostic score incorporating the number of resected lymph-nodes to predict recurrence and survival in non-small-cell lung cancer. Lung Cancer 2009;66:365-71.

10. Lee JG, Lee CY, Park IK, et al. Number of metastatic lymph nodes in resected non-small cell lung cancer predicts patient survival. Ann Thorac Surg 2008;85:211-15

11. Fujimoto $\mathbf{T}$, Cassivi SD, Yang $\mathrm{P}$, et al. Completely resected N1 non-small cell lung cancer: factors affecting recurrence and long-term survival. J Thorac Cardiovasc Surg 2006;132:499-506

12. Lee HY, Choi HJ, Park KJ, et al. Prognostic significance of metastatic lymph node ratio in node-positive colon carcinoma. Ann Surg Oncol 2007;14: 1712-17.

13. Vinh-Hung V, Verschraegen $\mathrm{C}$, Promish DI, et al. Ratios of involved nodes in early breast cancer. Breast Cancer Res 2004;6:R680-8.

14. Nitti D, Marchet A, Olivieri $M$, et al. Ratio between metastatic and examined lymph nodes is an independent prognostic factor after D2 resection for gastric cancer: analysis of a large European monoinstitutional experience. Ann Surg Oncol 2003;10:1077-85.

15. Herr HW. Superiority of ratio based lymph node staging for bladder cancer. J Urol 2003;169:943-5.

16. Berger AC, Sigurdson ER, LeVoyer $T$, et al. Colon cancer survival is associated with decreasing ratio of metastatic to examined lymph nodes. J Clin Oncol 2005;23:8706-12.

17. Klabunde $\mathbf{C N}$, Legler JM, Warren $\mathrm{JL}$, et al. A refined comorbidity measurement algorithm for claims-based studies of breast, prostate, colorectal, and lung cancer patients. Ann Epidemiol 2007;17:584-90.

18. Goldstraw $\mathbf{P}$, ed. Staging Manual in Thoracic Oncology. Orange Park FL: Editorial Rx Press, 2009.

19. Greenstein AJ, Litle VR, Swanson SJ, et al. Prognostic significance of the number of lymph node metastases in esophageal cancer. J Am Coll Surg 2008;206:239-46.

20. Virnig BA, Warren JL, Cooper GS, et al. Studying radiation therapy using SEER-Medicare-linked data. Med Care 2002;40(8 Suppl):IV-49-54.

21. Wisnivesky JP, Halm E, Bonomi M, et al. Effectiveness of radiation therapy fo elderly patients with unresected stage I and II non-small cell lung cancer. Am J Respir Crit Care Med 2010;181:264-9.

22. Warren JL, Harlan LC, Fahey A, et al. Utility of the SEER-Medicare data to identify chemotherapy use. Med Care 2002;40(8 Suppl):IV-55-61.

23. Ludwig MS, Goodman M, Miller DL, et al. Postoperative survival and the number of lymph nodes sampled during resection of node-negative non-small cell lung cancer Chest 2005;128:1545-50.

24. Khan $\mathbf{O A}$, Fitzgerald JJ, Field ML, et al. Histological determinants of survival in completely resected T1-2N1M0 nonsmall cell cancer of the lung. Ann Thorac Surg 2004;77:1173-8

25. Luzzi L, Voltolini L, Campione A, et al. Pneumonectomy vs lobectomy in the treatment of pathologic N1 NSCLC: could the type of surgical resection dictate survival? J Cardiovasc Surg (Torino) 2003;44:119-23.

26. The NCCN Clinical Practice Guidelines in Oncology: Non-small cell lung cancer (Version V.I.2010) http://www.nccn.org/professionals/physician_gls/f_guidelines.asp (accessed 7 Jul 2010). 
27. Arriagada R, Dunant A, Pignon JP, et al. Long-term results of the international adjuvant lung cancer trial evaluating adjuvant cisplatin-based chemotherapy in resected lung cancer. J Clin Oncol 2010;28:35-42.

28. Potti A, Mukherjee S, Petersen R, et al. A genomic strategy to refine prognosis in early-stage non-small-cell lung cancer. N Engl J Med 2006;355:570-80.

29. Chen HY, Yu SL, Chen $\mathrm{CH}$, et al. A five-gene signature and clinical outcome in non-small-cell lung cancer. N Engl J Med 2007;356:11-20.

30. Lau SK, Boutros PC, Pintilie M, et al. Three-gene prognostic classifier for early-stage non small-cell lung cancer. J Clin Oncol 2007:25:5562-9.

31. Varlotto JM, Recht A, Nikolov M, et al. Extent of lymphadenectomy and outcome for patients with stage I nonsmall cell lung cancer. Cancer 2009;115:851-8.
32. Percy C, Stanek E 3rd, Gloeckler L. Accuracy of cancer death certificates and its effect on cancer mortality statistics. Am J Public Health 1981;71: $242-50$.

33. Wisnivesky JP, Halm EA. Sex differences in lung cancer survival: do tumors behave differently in elderly women? J Clin Oncol 2007;25:1705-12.

34. Anon. Postoperative radiotherapy in non-small-cell lung cancer: systematic review and meta-analysis of individual patient data from nine randomised controlled trials. PORT Meta-analysis Trialists Group. Lancet 1998;352:257-63.

35. Shedden K, Taylor JM, Enkemann SA, et al. Gene expression-based survival prediction in lung adenocarcinoma: a multi-site, blinded validation study. Nat Med 2008;14:822-7.

\section{Have confidence in your decision making.}
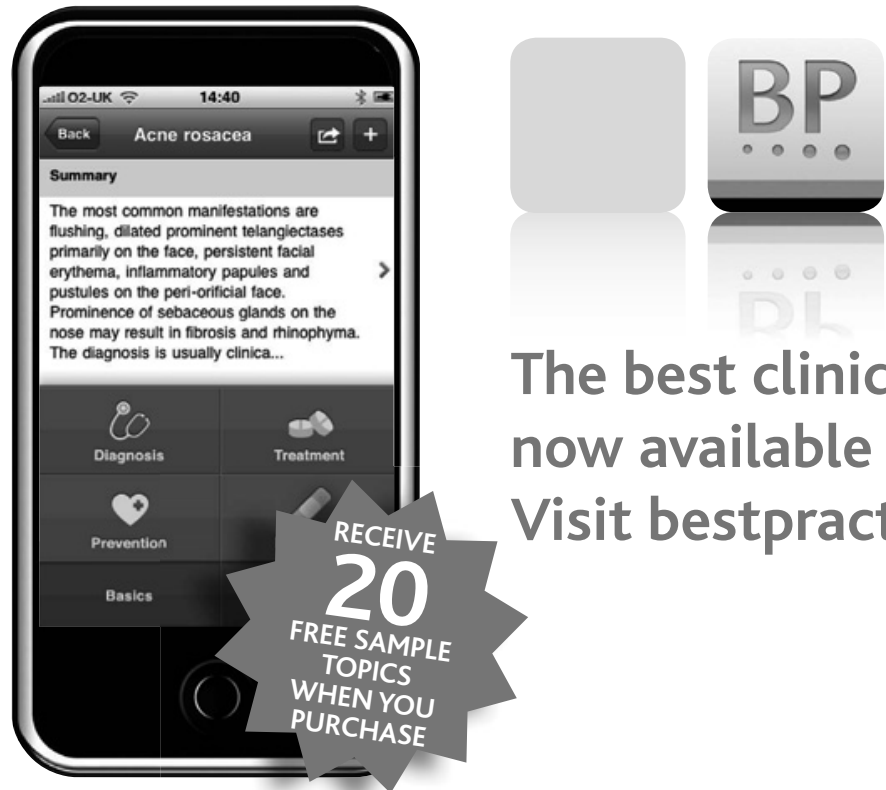

The best clinical decision support tool is now available as an app for your iPhone. Visit bestpractice.bmj.com/app

\section{clinicians $\bullet$ medical students $\bullet$ nurses $\bullet$ healthcare practitioners}

